\title{
LA RADIODIFUSIÓN Y LA FORMACIÓN DE CIUDADANOS: COLOMBIA 1920-1950
}

\author{
Alejandro Alvarez Gallego*
}

\begin{abstract}
RESUMEN - El artículo muestra el papel que jugó la radio en Colombia desde el momento de su aparición en el escenario social, su papel educativo y sus vínculos con el desarrollo industrial, con la configuración de las ciudades y con la necesidad de formar una identidad nacional. Hace énfasis en la forma como desde allí se cuestionó la educación formal impartida desde la escuela y en la aparición de un nuevo paradigma para la educación, relacionado con el surgimiento de la sociedad de masas. Desde entonces la educación sería un asunto social que trascendía la edad de los escolares y se debia proyectar a toda la población.

CONCEPTOS CLAVES - ciudad, educación de masas, formación de ciudadanos.
\end{abstract}

\begin{abstract}
The article approaches the educational role that radio stations have performed in the Colombian social scenery, since their emergence. Their ties with the industrial development, the configuration of the cities, and the need to form a national identity are highlighted. It is sought to emphasize how the formal education, unleashed by the schools, begins to be questioned through this tie and through the rise of a new paradigm for education, associated with the emergence of a mass society. After this moment, education would be a social matter that would transcend the age of the students, projecting itself to the population as a whole.
\end{abstract}

KEY WORDS - city, education of masses, formation of citizens.

\begin{abstract}
"La radio ha conquistado en el mundo, en veinticinco años, un lugar eminente. Se ha instalado en nuestras costumbres, ha penetrado y se ha impuesto en todas partes.... se le han asignado las más diversas tareas: la diversión, la lucha de ideas, los servicios de interés público, la educación y la cultura" (Clausse, uNESCO, 1949).
\end{abstract}

\section{La radio como fenómeno urbano, industrial y comercial}

La radio surgió durante los años veinte impulsada por la necesidad de aumentar la publicidad de los productos de las nuevas empresas comerciales e industriales que se consolidaban en el país en ese período (en medio de la recesión

* Licenciado en ciencias sociales y Magister en estudios políticos. Es profesor de la Universidad Pedagógica Nacional y miembro de la Sociedad Colombiana de Pedagogía. Este artículo hace parte de una investigación denominada "Ciudad, Educación y Escuela: 1930-1990" financiada por el Pedagógico Instituto para la Investigacion Educativa y el Desarrollo Pedagogico (IDEP) y la Secretaria de Educación de Santa Fe de Bogotá. 
económica que se vivía en E.U.); a finales de la década del treinta y comienzos de los cuarenta, el proceso de nacionalización de la industria se consolidó debido a la sustitución de importaciones que se produjo con la segunda guerra mundial. Motivados por la posibilidad de ampliar el mercado, los industriales colombianos invirtieron en este medio, con la convicción, no sólo de que sería rentable por sí misma (dadas las ganancias ocasionadas por la venta de publicidad), sino que la oportunidad de hacer la publicidad de los productos era una garantía de crecimiento para sus empresas. ${ }^{1}$

Los vínculos entre la clase política, el capital industrial y los medios de comunicación (hasta los años cincuenta hablamos de la prensa escrita y la radio), fueron muy claros desde el comienzo. El caso de la Cadena Radial Colombiana CARACOL ${ }^{2}$ es muy ilustrativo. Los antecedentes de esta cadena se relacionan con la creación, en 1945, de la "Radiodifusora Interamericana", una prolongación del periódico $E I$ Liberal, de propiedad del expresidente liberal Alfonso López Pumarejo y su hijo, también expresidente, Alfonso López Michelsen. Antes de salir al aire y con la inyección de capital que hiciera Coltejer, ${ }^{3}$ le cambiaron el nombre por el de "Emisoras Nuevo Mundo".

Por su parte los conservadores habían montado su propia emisora en 1936 "La Voz de Colombia". Laureano Gómez, también expresidente conservador, convirtió la emisora en una extensión del periódico El Siglo y su propósito era contrarrestar a través de este medio las acciones del gobierno liberal de López Pumarejo quien, a través del radioperiódico político La República Liberal", transmitido por "La Voz de la Victor", hacía proselitismo a su programa de gobierno.

Algunos datos nos muestran el rápido crecimiento de la radiodifusión, como corolario de las ventajas económicas que representaba y las posibilidades que brindaba para conseguir el ideal de progreso que se soñaban los dirigentes políticos: En 1940 había 13 emisoras en Bogotá y 8 en Medellín. En 1941 había 90 transmisores dedicados a la propaganda comercial y tres manejadas por el Estado: El de la Radiodifusora Nacional, el de la Universidad de Antioquia y el de la Intendencia del Chocó. En el mismo año había 70 emisoras registradas y en 1955 ya eran 109. En 1942 había 23 estaciones comerciales de onda corta, 71 de onda larga y 5 culturales, de las cuales 21 estaban en Bogotá y 14 en Medellín (Díaz, 1943, p. 258; Nieto, 1957, p. 34; Pareja, 1984, p. 95).

\section{Para educar a las masas la escuela no basta}

Los medios de comunicación (hasta el momento eran la radio, la prensa y el cine) aparecen como resultado de la complejización de la vida social y legan para

1 La inversión en la radiodifusión era una empresa prometedora, tal como lo estaba mostrando el caso norteamericano, donde de 9 millones de receptores producidos en 1929, se pasó en 1933 a 17 millones, con utilidades superiores a 39 millones de dólares. Ver: PAREJA, Reynaldo. Historia de la radio en Colombia, 1929-1980. Bogotá: Servicio Colombiano de Comunicación Social, 1984, p. 25.

2 Hoy en día CARACOl es una de las dos más grandes empresas de comunicación que hay en el país y controlan la mayoria de las emisoras radiales y de la programación televisada.

3 Coltejer fué hasta hace poco la industria textilera más importante del país, su dueño es actualmente quien controla uno de los grupos económicos más poderosos. 
cumplir una tarea educativa, supliendo los vacíos que estaba dejando la escuela; ésta habría sido diseñada para educar las masas, pero sus métodos no serían suficientes.

La escuela habría sido indispensable y suficiente hasta cuando los hombres podían apoyarse en las tradiciones y en los códigos de pensamiento y de acción elaborados por generaciones anteriores; desde esa perspectiva la escuela cumpliría una función conservadora, a la manera de Durkheim: la de transmitir a las nuevas generaciones el legado de las viejas. Y en efecto esto era lo que venia haciendo con más o menos eficacia; ella era la institución que por excelencia llenaba ese vacío. Pero lo que se necesitaba en ese momento, según el pensamiento de la época, era aprender a tomar decisiones inmediatas, frente a situaciones impredecibles, para lo cual el criterio de las viejas generaciones no bastaba.

\begin{abstract}
"La obra emprendida por la educación escolar encuentra hoy su continuación en la educación popular. Además la escuela ha abierto sus clases a nuevos medios de expresión, como la radio [...]. En cuanto a la educación popular, tuvo también que recurrir a instrumentos adaptados a una acción de masas. Sus métodos tradicionales, la conferencia, el concierto, la visita bajo la dirección de una guía, etc. han resultado manifiestamente insuficientes. La educación popular ha de disponer de medios de expresión que puedan llegar a las masas: la prensa, la radio y el cine."4
\end{abstract}

Según el autor, a pesar de que se intentaron renovar los métodos de enseñanza en la escuela, no dio abasto frente a nuevas exigencias muy propias de la sociedad de masas. Aunque originalmente el propósito era legar a enseñar todo a todos, llegó un momento en que el crecimiento de la población y la manera de asociarse en conglomerados urbanos, desbordó la posibilidad de la escuela. Por eso habrían surgido, más o menos espontáneamente, nuevas formas de educación popular, que atenderian a la población más allá de la escuela, pero que sobre todo tendrían la capacidad de llegar a un nuevo sujeto, diferente al individuo: las masas.

Otra faceta del problema, igualmente nos sirve para comprender la forma como en ese momento se justificaba la acción educativa de la radio:

"No puede haber desarrollo económico si no se eleva paralelamente el nivel general de la educación. Pero cuando se trata de realizar en unos años una labor que ha necesitado siglos en otros países, los métodos tradicionales de educación resultan por sí solos inadecuados y es necesario utilizar ampliamente todas las ventajas que ofrecen los medios de información de masas. Por ello el papel que puede desempeñar la radio en la educación fundamental es una cuestión de vital importancia en el mundo de nuestros días."5

El planteamiento parece completamente lógico. Su propuesta era utilizar los medios de comunicación, como la radio, para educar rápidamente la población, dado que teníamos un retraso de siglos en ese campo en relación con los países desarrollados, y esperar a que la escolarización lo lograra era demasiado tiempo. El elemento novedoso radica en el hecho de que le concede a la educación un papel definitivo en el desarrollo económico. Es una variable que luego los desarrollistas ampliarán profusamente durante las décadas siguientes.

4 CLAUSSE, Roger. La educación por la radio escolar. París: UNESCO, 1949, p. 13.

5 WLLLAMS, Grenfell. La radio y la educación fundamental en las regiones insuficientemente desarrolladas. Paris: UNESCO, 1950. 
Una vez se introdujo la radio en la cultura urbana, surgió otro problema, propio de aquellas agencias que tenían funciones educativas; en este caso comenzaron a surgir preguntas sobre la psicología del radioyente:

\begin{abstract}
"No existe ninguna psicología de los radioyentes. Estos permanecen aislados unos de otros, sin el contacto que desencadena una corriente de comunión y de simpatía. El oyente reacciona a la escucha radiofónica según los imperativos de su psicologia personal, y más particularmente en respuesta a las exigencias de sus gustos; ni siquiera sus hábitos de escucha reflejan otra cosa que su carácter de hombre aislado, separado de los demás por la distancia y los obstáculos."6
\end{abstract}

Se trata de una dificultad, que sería inherente a la radio, para controlar la manera de incidir en el comportamiento social de las personas. En la medida en que no es fácil reunir a grupos de personas para las audiencias radiales, las personas aisladas manejaría a su arbitrio el mensaje y el impacto sobre sus comportamientos nunca se podria controlar. Para nosotros, esta es quizás la particularidad de una educación de masas, controlada ahora, gracias al crecimiento urbano, por las nuevas tecnologías de la comunicación.

En las ciudades las personas están solas, aisladas, pero se diluyen en el fenómeno de la masa. La educación que se da en las ciudades, a través de los medios de comunicación, es anónima, a diferencia de lo que hacía la escuela, la familia o la Iglesia. Tal vez esto ya lo venía haciendo la literatura impresa que no estaba reguiada por estas tres instituciones, pero, aunque no hubiera forma de regular el aprendizaje de quienes leían la prensa diariamente, este medio no era suficientemente masivo, dado que leer era una destreza bastante más compleja que la de escuchar o ver. Lo que harán el cine, la radio y la televisión será realmente novedoso, e inaugurará una nueva época en la historia de la educación. Los medios atienden de manera original la nueva condición de la educación, a partir de esta nueva manera de ser sujetos en las ciudades, aunque también contribuyen a formar tal subjetividad.

La creación de la noción el público data de estos años y está ligado a los medios de comunicación. Es una noción útil para ubicar esta nueva subjetividad, entre la individualización y la masificación.

Ahora bien en el centro de esta categoría se encuentra también el concepto de información, tal como se planteaba en la Monografía de Medellín: "Estamos en el siglo de la información, por eso es también el siglo de la opinión pública." Entre informar y educar se va a crear un nuevo espacio que será ocupado por los medios, más que por la escuela.

Con el argumento de que la sociedad necesitaba información, la radio buscó posicionarse para resolver además dos problemas propios de la época: el de el mercado y el de lá nacionalidad. El público consume, en la lógica del mercado, pero la opinión pública constituye al ciudadano, en la nueva territorialidad urbana de la Nación.

6 Clausse, ob. cit.

7 Monografia de Medellín. Medéllín: Hemisferio, 1959, p. 244. 
El primero problema, ya lo analizamos, da cuenta de la forma como se crearon hábitos de consumo y necesidades personales que fueron satisfechos por los productos que promocionaba la radio. Para lograrlo fue necesario adecuar los horarios de transmisión al tiempo de las ciudades, por eso se ocuparon los horarios nocturnos y las primeras horas de la mañana, de tal manera que le llegara a esa audiencia urbana que laboraba a ritmo industrial y desarrollaba una vida social en la noche. Cercana a la necesidad de informar - formar ese mercado de consumidores, se encuentra la noción de masas (la sociedad de masas es una sociedad de consumidores, fundamentalmente, aunque también de movimientos sociales, como movimientos de masas, más cercano a lo político).

Las masas consumidoras no solo compran en el mercado, sino que significan lo que compran, movidos por los imaginarios que agencian los medios. Así, el deporte se masificará cuando la masa le da un significado y lo consume a través de la radio. Lo mismo va a suceder con la música. La introducción de varios géneros musicales, como el tango o la ranchera y luego el rock, que llegaron a difundirse ampliamente, son fenómenos producidos también por la radio. Alli se incorporan no solo gustos o preferencias estéticas, sino modos de ver el mundo. En ese proceso de interacción: individuo - masa - público - ciudad, se va configurando el nuevo paisaje cultural de nuestros países.

\title{
Vender o educar: entre lo comercial y lo cultural
}

Cuando apareció en el aire la emisora H.J.C.K., El Mundo en Bogotá8 (15 de septiembre de 1950), por iniciativa de un grupo de amigos encabezados por Eduardo Caballero Calderón, Alvaro Castaño Castillo, Bernardo Romero Lozano, Gloria Valencia de Castaño ${ }^{9}$ quienes compraron la Radio Granadina, la emisora tenía como propósito programar...

\begin{abstract}
"Música de los grandes maestros y espacios radiales de humor, combinaciones de música y libretos especiales, dramatizaciones, comentarios culturales, nacionales e internacionales. La parte comercial tratada con discreción y sobriedad, buscando llegar al oyente a través del anuncio circunstancial. Como modalidad especial en este aspecto comercial se rechazó la cuña cantada, objeto de debates y criticas en la prensa del pais. Los propósitos que guían a los empresarios de la nueva radio-emisora, tienen como cuestión central la de darle a los programas un fondo cultural que no excluye ni se haya en pugna, como se ha supuesto con mucha frecuencia, el aspecto comercial del negocio." 10
\end{abstract}

La H.J.C.K. se convirtió en una tendencia representativa del punto de vista más crítico de la radio comercial. Se erigió en el ejemplo de lo que sería una emisora eminentemente cultural, en medio de un sistema de radiodifusión que dependía del patrocinio de los anunciadores. Los otros ejemplos, como la radiodifusora nacional o las emisoras universitarias, siendo también de corte cultural, estaban subvencionadas.

8 Esta emisora todavia existe y representa un estilo de radio muy particular, pues se dedica exclusivamente a difundir la música clásica y programas culturales del mundo de la élite "culta".

9 Se trata de escritores, directores de programadoras de radio y televisión y comentaristas que aún juegan un papel protagónico en el mundo de la farándula artística y cultural en Colombia.

10 Revista Semana, Bogotá, v. 9, n. 205, p. 25-27, sep. 1950. 
La discusión que había detrás era acerca de la función educativa de la radio. Ante el reconocimiento del impacto que tenía sobre el comportamiento de la población, y por lo tanto de su papel como moldeadora de la cultura, era inevitable que las diferentes posturas ideológicas presentes en la sociedad de la época se pronunciaran al respecto.

El reclamo frente a la radio comercial consistia en que no se preocupaba por elevar el nivel cultural del pueblo, con la disculpa de que para tener audiencia había que complacer los gustos del público, y esto era condición para obtener el patrocinio de los anunciantes. Se trataba de una discusión sin salida, pero que develaba un hecho: el posicionamiento de la radio como agencia movilizadora de intereses, prácticas y discursos propios de la sociedad que emergía en torno a la industrialización y al consabido crecimiento de las ciudades.

Las innumerables críticas se podrían resumir en frases como estas:

\begin{abstract}
"Se quejan los padres de familia que ya no estudian sus hijos por escuchar esas necedades de mal gusto (se refieren a las radio-novelas) en las cuales se observa una notoria ausencia de gusto, un atentado contra la gramática, una violación de la literatura y un desierto de ideas que pasma." 11

"Hemos notado que algunas emisoras de Bogotá y Medellín - en cambio en Manizales insisten y en Cali aumentan - han rebajado la densidad de la cursilería. Nos referimos a la radio-transmisión de ciertos programas novelescos absurdos, todo lo cual ha hecho que ciertas pasiones e instintos se propaguen y que la niñez, sobre todo, se infecte del virus que inocula esa literatura pedestre, casi vargasvilesca que escriben algunos redactores de pacotilla para ganarse unos pesos y para desacreditarse lo suficientemente como $\{\ldots\}$ escritores." 12
\end{abstract}

Hay aquí una doble preocupación, la del impacto de la radiodifusión sobre la educación de la infancia, que está relacionada con la competencia que esto le significaba a la escuela, escenario que sí estaba controlado por el Estado y por la moral religiosa. Pero a esta preocupación se le agrega una segunda y es la idea de que las pasiones y los instintos (muy bien controlados en la escuela) son un virus, y como todo virus, se transmite por contacto directo. Las radio novelas a las que alude la nota también tenían una función educativa implícita, que los representantes de las buenas costumbres se encargaban de explicitar.

Lo que estaba en juego era el control moral de la población y la intervención sobre las agencias educativas que había introducido la ciudad, pero este propósito se estaba convirtiendo en una acción difícil, dado que no tenían la misma potestad que habían conquistado sobre la escuela y sobre la familia, instituciones que ya no eran suficientes para garantizar el orden moral que deseaban algunos defensores del interés público.

Toda esta discusión, como decíemos arriba, estaba atravesada en el fondo por la concepción que se tenía sobre educación. En medio del debate había quien intentara aclarar la confusión que se presentaba con respecto a la pregunta: ¿Quién educa? La angustia que se sentía era por la indefinición del papel que asumiria la escuela, una vez instalado en la sociedad un medio de comunicación como el de la radio. Ante esta angustia se dieron tres tipos de respuestas: la primera, más o

11 Revista Gentes, año 7, v. 6, n. 55, p. 5, jul. 1956.

12 Revista Gentes, ob. cit. 
menos tranquilizadora, era la de diferenciar el tipo de educación que se practicaba por fuera de la escuela de la que seguía siendo propiamente escolar; con esto se le redefinía el papel y se libraba de ciertas responsabilidades. Su función, ahora más modesta, seguramente seguiría siendo conservadora, y reaccionaria, en tanto que respondía a una amenaza. La otra respuesta era la de introducir la radio en la escuela, tal como se intentó hacer con el cine, con el fin de hacer un uso didáctico de ella. Finalmente se intentaría escolarizar la radio, utilizándola como medio para reproducir lo que se hacía en la escuela (alfabetización por radio, programas de concurso, campañas educativas y moralizadoras...). 